\title{
A study of indicators of willingness in the knowledge
}

\section{transfer process}

\section{YingFei Héliot}

School of Management, Faculty of Management and Law, University of Surrey Guildford.UK

\section{Michael Riley}

School of Management, Faculty of Management and Law, University of Surrey Guildford.UK 


\begin{abstract}
The literature on knowledge transfer is confident in its assertion that a 'stickiness' pervades knowledge disclosure process. This phenomenon is often attributed to structural communication barriers but an equally valid explanation could stem from the individual feeling a sense of ownership of their knowledge which then engenders a reluctance to be open about their knowledge within a formal knowledge transfer process. We pursue this idea theoretically through notions of possessiveness and psychological ownership; and empirically by exploring the concept of willingness to disclose. Assuming willingness to be unidimensional a methodology is put forward that uses indicators to measures its direction. Using a sample of 1050 UK engineers we illustrate the direction of willingness on a reluctance- willing dimension. We argue that knowledge transfer requires management to examine more closely the stimuli that affect the process.
\end{abstract}

Keywords: willingness; knowledge; psychological ownership; possessiveness; engineers; knowledge transfer 
This paper describes an exploratory study of the willingness of individuals to disclose and exchange knowledge in the knowledge transfer process. There has been a tendency within the literature to take a number of individual level factors for granted (for example, willingness) by appearing to assume that knowledge transfer is automatic once procedures are in place and structural and communication impediments have been overcome. We argue that this is not the case because once the individual is placed at the centre of the knowledge transfer process the assumption becomes unrealistic. We acknowledge that willingness is a malleable entity that can be influenced and therefore accept that social and political aspects of any exchange situation may influence the willingness of individual. However, we make a case for an intrinsic form of influence and suggest that irrespective of social pressure, the individual will express a natural reticence or reluctance to simply disclose or exchange their knowledge even in accommodating collaborative frameworks (Huxham \& Vangen 2001). This rationale is supported by the 'stickiness' observed in the knowledge management literature in which knowledge is reluctant to flow between workers (Szulanski 1996). Whilst such stickiness is often attributed to structural communication difficulties, one equally plausible explanation could be that it emanates from a personal reluctance to divulge, stemming from a sense of psychologically ownership of knowledge (Dirks, Cummings \& Pierce 1996). This is the theoretical stance taken in this paper.

Our emphasis, following the line of Lam (2000), acknowledges different types of knowledge and the fact that they can be held individually and collectively. However, notwithstanding the type of knowledge and allowing for the degree of awareness of that knowledge, we argue that disclosing or exchanging such knowledge is not an automatic process. We draw a distinction between willingness to collaborate and 
actually being prepared to divulge knowledge on the grounds that even in collaborative frameworks the individual's propensity still matters.

Szulanski's (1996) notion of 'internal stickiness' is a useful starting point because of his concern for barriers to knowledge transfer. We note that he emphasises ambiguity and comprehension as communication uncertainties but also that he attributes little influence to personal motivation. We concur with Szulanski in that the process of knowledge transfer is not automatic, but, we go further to argue that psychological ownership of knowledge has an intervening role in the individual's willingness to disclose knowledge; this is the basic premise which drives the theoretical and conceptual arguments in this paper. We examine psychological ownership from an individualistic perspective through the literature that explores feelings of possessiveness, the sense of 'mine', and make a connection between the feelings of possessiveness and willingness to disclose knowledge. The arguments fully recognise the legal and organisational rights within knowledge transfer processes but emphasis that there is a human element within those processes. The theoretical analysis which follows begins by examining the nature of willingness then draws in the notion of possessiveness and makes a case that knowledge can be possessed. At this juncture the arguments are introduced to the context of knowledge transfer process. A central issue here is the difference between collaborative tendencies (willingness to participate) and willingness to disclose and transfer knowledge. The empirical study described is an attempt to find a way of measuring individuals' willingness. It is based on a sample of UK engineers on the grounds that they represent a diverse skill set within a common nomenclature that have high levels of human capital and are regularly involved in knowledge transfer processes. 


\section{WILLINGNESS AND KNOWLEDGE}

The literature on willingness is normally context specific in that it is attached to an action (willingness to pay; willingness to accept). However, when confined to the concept of willingness itself, the literature is limited and has a problem with its definition because it is often taken for granted. In its simplest form willingness can be conceived as a freedom from reluctance (Kahn 1990; May, Gilson \& Harter 2004). Yet, it is not uncommon for the concept simply to be subsumed within the attitude/behaviour prediction relationship as intentionality (see for example: Aryee, Chay \& Chew 1996; Gallucci \& Perugini 2003; Landau, Shamir \& Arthur 1992; Morgan, Miller \& Arasaratnam 2003; Stilwell, Liden, Parsons \& Deconinck 1998). We take the position that the measurement of intention, which normally is captured through being directed at an object (as in market research), does not represent or capture the broader concept of willingness. Putting aside the limitations of definitions, there are three aspects of willingness that relate to our interest in the stickiness found in knowledge transfer: firstly, the effect of social identification on collective action in which the individual first decides to participate in a group activity; an act which pre-ordains a degree of disclosure of knowledge. Secondly, there is the issue of reciprocity and exchange. Thirdly, there is the social and political pressure which others can exert on the individual's willingness which can both lower the propensity to disclose knowledge and cause the individual to question the legitimacy of the knowledge itself (Walsh, Henderson \& Deighton 1988).

The willingness of an individual to engage in collective action or in a collaborative framework is seen as a measure of their identification with that group (Fosh 1993; Kelly \& Kelly 1994). We argue that such identification is a facilitative environment that might induce knowledge exchange but it does not guarantee it. The 
stickiness arguments are largely founded on conditions within the organisation that militate against collaboration such as, high 'power distance' (Guzman \& Wilson 2005) and uneven power distribution (Darrah 1996). Coopey and Burgoyne (2000) argue that a particular political climate would facilitate learning and cooperation but do not touch directly on individual motives with the arguments remaining in the social domain. Goh (2002) is more specific in arguing that motives are part of the framework by which management integrate knowledge. Molm (1994) raises the case of interdependence and suggests that a structure of reciprocal dependence is a defining characteristic of all social relations based on exchange; we see this only as a starting point. Gallucci and Perugini (2003) put the structural arguments to one side in emphasizing that reciprocity between individuals is a valence based relationship; something of value has to be exchangeable. They go further to argue that reciprocity is a 'natural tendency' which they term 'propensity to reciprocity', in other words, the tendency is a personality variable. We make no such claims in our empirical study but take on board the possible influence of receiving knowledge as an incentive to exchange.

\section{KNOWLEDGE AND THE NOTION OF POSSESSIVENESS}

The argument that knowledge can be possessed is in one sense obvious in that tacit knowledge can be embedded within practice but our arguments refer to knowledge which is conscious and available to awareness. It is this knowledge that has the capacity to be favoured and valued. By taking this position we do not imply that only knowledge that is conscious and valued is relevant to knowledge transfer. Some knowledge is not communicable and some only exchangeable by face to face practical working (Von Krogh, Ichijo \& Nonaka 2000; Birkinshaw, Nobel \& Ridderstrale 
2002). Reber (1993), following the line of Polanyi (1964), points out that tacit knowledge is often unconscious knowledge because it is contained within practice and is therefore only communicable indirectly through demonstration (e.g. riding a bicycle). Similarly, organisational cognition would argue that tacit knowledge is contained within activity systems (work systems and routines) that represents a collective mind in that the system itself only works because of a shared interdependence of knowledge between group members made explicit only through interaction (Weick \& Roberts 1993).

Concerns about the type of knowledge and its location are important but, for any knowledge to be regarded as a possession, it has to have two properties attached to it by its owner, namely, that they are favoured and that they represent the individual in terms of their self identity. Leading logically from this position is the question as of if knowledge can be psychologically possessed, then can it play a part in an individuals' willingness to disclose their knowledge.

Possessiveness is about psychological ownership which involves the valuation of something in terms of the self. Furby (1991) refers to it as the 'psychology of mine'. Possessions not only give a sense of control (Rudmin 1993: 55) but also a feeling of continuity and security (Steiner 1978; Pierce, Kostova \& Dirks 2003). These feelings transmit themselves into behaviour which can be constructive but also dysfunctional with effects such as failing to give away information (Burke \& Reitzes 1991). However, we argue that it is the tendency to favour what is felt to be possessed that has influence on the willingness to disclose and exchange knowledge (Nuttin 1987; Formanek 1991; Beggan 1992). This would be especially strong when an individual had created new knowledge. It would be surprising if they did not feel a sense of attachment to it (Newell, Robertson, 
Scarborough \& Swan 2002). Notwithstanding the above arguments, the question as to whether knowledge can be seen as a possession in the same way as a physical object is an unresolved issue. In this respect we highlight the arguments of Bernstein (2000) who argued that knowledge can be internalised. For Bernstein, knowledge was an outer expression of an inner relationship. The inner relationship was a guarantee of the legitimacy, integrity, worthwhileness and value of the knowledge. Our assumption is that to be internalised the knowledge has, in some way, to be valued and that if valued it can be regarded as a psychological possession which forms an inner meaning to one self. One possible value that can be placed on knowledge is that of utility, that is, valued for its usefulness. The concept of usefulness grants to knowledge an instrumental purpose; something has to be achieved. The achievement can be an action or a thought or both but in either case the knowledge has a value. It can be a practical goal or, the exploration of some theoretical or, even an abstract concept (Scribner 1986). Usefulness as a value relates to a possession's role in providing necessary functions such as status and identity (Prentice 1987). We suggest that if knowledge is to be considered as a possession then it must be, in some way and for some purpose, be valued.

\section{KNOWLEDGE TRANSFER}

There is no shortage of literature on best practice, transfer models and strategies for the process of knowledge transfer (Parsons 2004; Sammons 2005; Svensson 2000). Furthermore, the model of Socialisation, Externalisation, Combination, and Internalisation (SECI) (Nonaka \& Takeuchi 1995) is well recognised and influential in the managerial literature (e.g. Sullivan \& Nonaka 1986; Magnus \& Morgan 1999; Baumard 1999; Von Krogh, Ichijo \& Nonaka 2000; Wang, Tong \& Koh 2003). The 
model contains a dynamic process in which explicit and tacit knowledge are exchanged and transformed. The fact that knowledge transfer is at the heart of technological and therefore economic, progress is not in doubt (Dayasindhu 2002; Osterloh and Frey 2000). Nor is there any question that such exchange requires mechanisms that have structure. The literature shows that such structures, both legal and organisational, exist and are, to varying extents, effective. However, it is also clear that structures themselves depend on the cooperation of the people involved (Mills, Hall, Leidecker \& Margulies 1983; Morris \& Empson 1998; Watson \& Hewett 2006). Cooperation itself is a process that does not imply agreement but does, indirectly, suggest that willingness is part of the dynamics of that process. Our arguments extend this line of thinking.

This requires an individualistic perspective which is, to an extent, neglected in the literature (See Johnson-Laird 1983; Zander 1991; Garavelli, Gorgoglione \& Scozzi, 2002 for exceptions that touch on the psychology of knowledge transfer). The managerial literature, for example, explicitly discusses how to deal with the transfer of knowledge as if it were an automatic process (Badaracco 1991; O’Dell \& Grayson 1998). In a sense, this propensity is understandable because knowledge transfer is imbued with ownership issues which have strong legal and organizational connotations attached. Who owns the knowledge to be transferred is open for interpretation.

\section{METHODOLOGY}

\section{Development of the willingness indicators}

The problem with measuring willingness is that the literature makes no strong assumption about whether the concept is holistic or one which contains components. 
In other words, research is left with having to assume unidimensionality because it is not certain of the existence of, and the identity of, possible components of a multidimensional construct. In these circumstances a method is needed which describes the concept without assuming to define it. Furthermore, the fact that willingness and willpower are common figures of speech only serves to indicate that willingness is not a fixed quantity but a pliable property that can be influenced. This adds to the complexity of the task for methodology but also gives a clue as to how it can be measured. The fact that it can be influenced by stimuli that trigger motives suggest that measuring for the effect of these influences is a way of indicating the existence of the phenomenon of willingness. This is the approach taken in this study.

Parallels with other psychological entities are not easy to establish. At one level the problems of measurement can be seen as similar to those of "satisfaction measurement' in that there are no indications of absolute level of magnitude. There is the issue of negative and positive values and the question of whether the concept can be considered continuous or discontinuous. Can unwillingness be assumed to be the contrasting pole to willingness? Satisfaction measurement is focussed on an object (noun) and can be measured both holistically and through components using probability assumptions which can be verified through internal consistency measures. This is not possible in the case of willingness as we simply do not know the nature of any components it might have, as discussed previously in the literature review.

In this study we assume that 'in action' there is such an entity as 'willingness' but that it can not be measured directly but can be inferred by indicators that influence it. Therefore we opted for a different approach based on the property of direction and we developed indicators of influence based on an assumption of a continuum running from mild positive inclination to strong positive inclination. We are not assuming a 
negative pole because there is empirical evidence to suggest that reluctance is the opposite of willingness. The devised indicators are not attributes of the entity but merely indicators of the direction it is pointing. We measure the distance between the indicators as a way of establishing a pattern and it is the direction of the pattern that is important not the actual standardised distances between the indicators. Direction is the important concept here but magnitude may be inferred by the clustering of indicators in one direction or the other.

The development process which produced eight willingness indicators was conducted through a focus group of academic engineers from a UK university $(N=10)$. The focus group was asked to discuss knowledge exchange between academics and between universities and industry in terms of the individual engineer involved in the process. The discussion was empowered to look, on the one hand, at the structural issues involved in the process; in this respect the group worked through their personal experiences of institutional issues. On the other hand, the discussion was encourages to explore knowledge in terms of individual need (Isabella 1990) particularly the way it functions in facilitating collaboration, enabling performance, granting status and having intrinsic value that enhances self-worth. Again the discussion resolved around personal experiences in dealing with research teams, colleagues and the media. The indicators emerged from the discussion and the facilitator constantly asked the group for consensus on each indicator. There was a consensus reached on eight indicators of willingness; which were;

1. If there were no competition

2. If I could trust my colleagues

3. If I had legal guarantees and permissions

4. If I had a financial incentive 
5. If it would enhance my professional standing

6. If it would make me well known

7. If I would receive new knowledge in exchange

8. If I were fairly treated by my employer

They represent structural (1.3.4) communication (7) and personal $(2,5,6,8)$ influences at an individual level.

\section{Sampling strategy and structure}

The study was conducted on qualified engineers that is, on engineers who had attained academic certification by a chartered professional association. The selection of engineers was based on the assumption of high levels of human capital and a strong likelihood of involvement in knowledge transfer processes. With the cooperation of six major professional associations within the UK an on-line survey was conducted and a total of 2242 engineers responded. The survey produced 1050 responses (47\% response rate) from professional engineers working in the UK; this forms the overall sample for analysis $(\mathrm{N}=1050)$. The sample was inclusive of the following engineering specialisations: chemical $(N=127)$, civil $(N=93)$, computer $(N=54)$, electronic $(N=166)$, mechanical $(N=103)$, process $(N=33)$, scientific $(N=78)$ and structural engineers $(N=349)$. A number of engineers who completed the survey did not identify their engineering category $(N=47)$.

\section{The application of the indicators}

In order to give the measurement the essential property of direction the indicators were measured on a 7 point scale along the construct 'most positive willingness to 
disclose knowledge - Least positive willingness to disclose knowledge'. We make no assumption about the polar dimensions of willingness and thus the scale is couched in positive terms and thus implies that reluctance is a diminished amount of positive feeling rather than a negative feeling. The conditions of the study meant that there was an assumption of unidimensionality but no assumption of equal intervals in the scaling. The problem therefore was to find a method of standardisation which could meet these conditions. The study takes an ordered category approach using Green's successive category method to standardise the distance scale (Dunn-Rankin 1983), this method uses accumulated proportions to create standardised category boundaries whilst giving each indicator an equal chance of influencing willingness. The judgements of the sample on each indicator are assumed to be normally distributed.

The data processing is in three phases; the production of a set of cumulative probabilities; the creation of category boundaries and then the allocation of average indicator score to the boundary set. Firstly, the raw scores are translated into a cumulative distribution. This is converted into a cumulative frequency distributed which is then turned into a set of cumulative probabilities. The probabilities are then converted into z scores. Table 1 displays the cumulative proportions as z scores.

\section{[Insert Table 1 here]}

The second phase is to create boundaries. These are calculated by subtracting each column score $(2-1,3-2 \ldots 7-6$; example $2-1$ on indicator 1 is $-1.03-0.70=0.33)$ and the average difference between the column is then accumulated to form the boundary between the categories. Table 2 displays the differences between the categories 


\section{[Insert Table 2 here]}

Assuming the first boundary as equal to zero, to obtain the category boundaries (B) the mean score for each boundary is summed as follows;

$$
\begin{array}{ll}
\mathrm{B} 1=0 & \\
\mathrm{~B} 2=0 ; 33: & 0.33 \\
\mathrm{~B} 3=0 ; 33 ; 21: & \\
\mathrm{B} 4=0 ; 33 ; 21 ; 47 ; & 1.01 \\
\mathrm{~B} 5=0 ; 33 ; 21 ; 47 ; 43 ; & 1.46 \\
\text { B6 }+0 ; 33 ; 21 ; 47 ; 43 ; 71 ; 2.15
\end{array}
$$

The scale range runs from 0.33 to 2.15 . The last column in Table 2 shows the boundary distance if equal intervals had been a legitimate assumption (0.43).

The final stage is to obtain the scale scores. This is done by subtracting the $\mathrm{z}$ score for each indicator from each boundary score then averaging it. This gives an average distance score for each indicator when placed against this standardised scale. In other words, the output is a rank order which places each indicator against a set of category boundaries founded on a standardised distance continuum. Table 3 shows the boundaries minus the $\mathrm{z}$ scores from table 1 
The column on the right indicates the score the sample registered for each of the eight indicators.

The main rationale for using Green's successive categories approach is that the study is measuring willingness indirectly and assuming the willingness statements are discrete conditions or influences but not attributes. As discrete conditions they will have a differential influence and this is represented by the distance between them.

Figure 1 illustrates the estimated distance of the eight indicator statements placed within the overall sample. Each interval score is a representation of the estimated distance of the statement from both poles.

\section{[Insert Figure 1 here]}

Figure 1 shows the direction of the indicators is towards the stronger positive pole but not emphatically so. This clustering may be due to sample variation but may also represent the abstract nature of the questions asked because there was no identified objective piece of knowledge for the sample to focus their possessiveness upon. Interpretation involves judging the rank order and the placing of the items in respect of the higher pole. In detail, the results for the overall sample show that the indicator 3 (interval score $=1.42$ ) 'if I had legal guarantees and permissions' and indicator 7 (interval score $=1.38$ ) 'if I would receive new knowledge in exchange' exert the most positive influence on willingness toward disclose knowledge. The predominance of these indicators may be due to the sense in which they capture the fundamental ideas of propriety and reciprocity which emanate from the literature. By contrast indicator 6 'if it would make me well known' is an indicator of the least positive willingness 
towards disclosure of knowledge; which suggests knowledge ownership is linked to a sense of self and through that, possibly to a sense of privacy. The original focus group created this indicator through being able to give examples of engineers who used their knowledge to promote themselves; this aspect was recognized but not approved of. The interval scores revealed a clear distance between wanting knowledge in exchange and needing a financial incentive. Whether differences in the positioning of these indicators represent a kind of architecture of stickiness is worth speculation but is doubtful. What is clear is that these indicators/conditions can be differentiated by the sample and as such the differentiation can be interpreted in terms of motives that lie behind the pattern.

The indicators have two properties that make them useful to the interpretation of knowledge transfer exchanges; firstly that they are directional without being value specific. They can however, be interpreted in terms of positive and negative depending on circumstances. Secondly, they are individual measures taken externally from any context. The significance of indicators of this type to the knowledge transfer process is, that as they are external to any particular knowledge transfer, they can be used to interpret the levels of exchange enacted. Many studies of knowledge transfer fall into two categories; those that infer the need for willingness but do not actually measure it (Watson \& Hewett 2006; Singh \& Premarajan 2007) and those that simply assume it to be there. Even tacit knowledge requires willingness when formally channelled. For example, in describing practical methods of disseminating tacit knowledge Smith, McKeen, and Singh (2007) fail to acknowledge that the various practices they propose still require a willingness to share. Studies from an organisational perspective often argue a case for trust and culture as the basis of exchange. In this type of study willingness is seen as not only a necessity for 
achieving knowledge transfer goals but as a bedrock of trust itself; yet it is inferred rather measured directly (Zhikun, Fungfai \& Qiying 2007). Very detailed studies such as that of Carlisle (2002) on knowledge boundaries raise the issue that willingness is part of a wider and complex process and not in itself sufficient to ensure successful cooperative output. Willingness is part of the process but is not solely derived from interaction within that process. It is for this reason we argue that, if we are to understand and interpret levels and forms of disclosure and exchange in particular circumstances then we need to know what the individuals bring to the situation. This argument is supported by the theoretical discussion on possessiveness and identity.

\section{DISCUSSION AND CONCLUSION}

The purpose of the study has been to bring the human element to the forefront of knowledge transfer: to recognise that individual biases matter. We argue that, notwithstanding the ambiguity and complexity of a collaborative framework, such as that described by Huxham and Vangen (2001), the personal willingness to disclose and exchange knowledge is a discrete area of concern to research in this field. Our arguments that propagate the individual as the locus of knowledge are contestable (Felin \& Hesterly 2007). For example, Cook and Brown (1999) argue that the individual locus of knowledge has been too influential and is dangerous to an integrated approach. This argument is itself contested by Van de Ven and Johnson (2006) who, in the context of knowledge transfer point out the role of individual differences and gaps in knowledge are sources of new knowledge creation. In asserting the primacy of the individual we are not denying the social constructivist 
argument that knowledge is a social phenomenon that is different from the aggregation of individuals (Nahapiet \& Ghoshal 1998:246). Nor do we dispute the collectivist view that knowledge can be held within a group (Halbwach 1992). We are however arguing that, notwithstanding the nature and source of knowledge, the individual can be aware of it, use it and have feelings towards it; one of which may be possessiveness.

The empirical study has shown a differential influence of indicators which can be interpreted in terms of motives and as potential barriers to knowledge transfer. The nature of these indicators is that of a predicted environmental response to the contemplated act of knowledge transference. In this sense they have the character of motivational stimulus-response but in this case the response is anticipated not enacted. If I disclose my knowledge I may get a particular response, for example, an enhancement of my personal standing within a group or a substantive financial reward. By contrast the absence of positive environmental signals may lead to the anticipation of no response in which case, the indicators may be a barrier to knowledge transfer. Either way the individual's response will be moderated by the level of valence attached to the indicators, for example, the absence of financial reward for an individual who attached a high valence to that stimulus may create reluctance. Similarly, an individual may not wish to be well known even if the environmental situation would mean that knowledge disclosure would have that effect. We accept the limitation of the study that there was no guarantee that subjects had actually taken part in formal knowledge transfer processes but argue that engineering roles are commonly conceived within collaborative frameworks. We also accept that the study does not resolve such issues as the polar nature of willingness or the question of magnitude but does address the direction of the phenomenon. 
The particular indicators generated by the study require further research and refinement. They may not be representative in all circumstances and they are unlikely to be comprehensive. Research on identifying indicators that influence willingness in relation to knowledge transfer processes is, we believe, a worthwhile research agenda. Would the indicators change or appear in a different pattern through the influence of organisational contexts, technological specificity or by the nature of the transfer process itself? The theoretical underpinning of the study suggests that further research is necessary to connect the idea of knowledge as a possession or the sense of ownership of knowledge with, on the one hand, the indicators of willingness and on the other, with competing claims for the locus of ownership such as the organisation. This approach could be built around theories that connect professional identity or organisational identity to the salience of knowledge (Gao \& Riley 2009). Of particularly value would be research which identified the realm of motives that are salient to knowledge transfer. This approach could be augmented further by studies based on theories from the psychological perspective that relate personal strategies and motives to employment (Rousseau 2005). The study described here was not context specific but the methodological approach would be applicable to specific circumstances. We argue that research on the individual within knowledge transfer processes is essential to understanding the dynamics of the process. In methodological terms, our contribution is that we have demonstrated one approach to quantifying the concept of willingness.

It is perhaps unfair to suggest that management take the individual for granted in formal knowledge transfer processes but we contend that a focus on the individual's motives in relation to their knowledge should be of primary concern in the 
management of these processes. Emphasis on creating the right environment is not, we suggest, sufficient to address the problem.

\section{ACKNOWLEDGEMENTS}

This study was completed through the cooperation of the following engineering associations; Institution of Civil Engineers, Institution of Electrical Engineers, Institution of Chemical Engineers, Institution of Structural Engineers, Institution of Structural Engineers, and Royal Academy Society Engineer Council UK.

\section{References}

Aryee S, Chay YW and Chew, J (1996). An investigation of the willingness of managerial employment to accept an expatriate assignment, Journal of Organizational Behavior, 17(3): 267-283.

Badaracco JL (1991) Alliances speed knowledge transfer, Planning Review, MarchApril: 10-16.

Baumard P (1999) Tacit knowledge in organisations, Sage, London.

Beggan, JK (1992) On the social nature of non-social perceptions: the mere ownership effect, Journal of Personality and Social Psychology, 62 (2): 229237.

Bernstein, B (2000). Pedagogy, symbolic control and identity, rev. ed., Lanham, Rowman \& Littlefield.

Birkinshaw, J, Nobel R and Ridderstrale, J (2002) Knowledge as a contingency variable: do the characteristics of knowledge predict organisation structure, Organization Science, 13 (3): 274-289.

Burke, PJ and Reitzes, DC (1991) An identity theory approach to commitment, Social Psychology Quarterly, 54: 239-251.

Carlile, PC. (2002) A Pragmatic View of Knowledge and Boundaries; Boundary Objects in new Product Development, Organisation Science, 13, pp. 442-455.

Cook, SDN, and Brown, JS (1999) Bridging epistemologies: the generative dance between organizational knowledge and organizational knowing. Organization Science, 10 (4): 381-400.

Coopey, J and Burgoyne, J (2000) Politics and Organizational Learning, Journal of Management Studies, 37(6): 869-885.

Darrah C N (1996) Learning and work; an exploration in industrial ethnography, New York, Garland Publishing. 
Dayasindhu, N. (2002). Embeddeness, knowledge transfer, industry clusters and global competitiveness: a case study of the Indian software industry. Technovation, 22, 551-560.

Dirks KT, Cummings, LL and Pierce, JL (1996) Psychological ownership in organizations: conditions under which individuals promote and resist change. In R. W. Woodman, \& W. A. Pasmore, (Eds.), Research in organizational change and development. 9. Greenwich, CT: JAI Press.

Dunn-Rankin P (1983) Scaling methods, New Jersey, Lawrence Erlbaum Associates.

Felin T and Hesterley, WS (2007) The knowledge-based view, nested herterogeneity, and the new creation: philosophical considerations on the locus of knowledge, Academy of Management Review, 32 (1): 195-218.

Formanek R (1991) Why they collect: collectors reveal their motivations, Journal of Social Behavior and Personality, 6: 275-286.

Fosh P (1993) Membership participation in work-place unionism: the possibility of union renewal, British Journal of Industrial Relations, 31: 577-592.

Furby L (1991) Understanding the psychology of possession and ownership: a personal memoir and an appraisal of our progress, Journal of Social Behavior and Personality, 6: 457-463.

Gallucci M and Perugini M (2003) Information seeking and reciprocity: a transformational analysis, European Journal of Social Psychology, 33 (4): 473495.

Garavelli AC, Gorgoglione M and Scozzi B (2002) Managing knowledge transfer by knowledge technologies, Technovation, 22:269-279.

Gao Y and Riley M (2009) Identity and knowledge: a review, International Journal of Management Reviews, forthcoming.

Goh SC (2002) Managing effective knowledge transfer: an integrative framework and some practice implications, Journal of Knowledge Management, 6 (1):23-30.

Guzman G and Wilson J (2005) The soft dimension of organizational knowledge transfer, Journal of Management Knowledge 9 (2): 59-74

Halbwach M (1992) On collective memory, Chicago, University of Chicago Press.

Huxham C and Vangen S (2001) What makes practitioners tick? understanding collaboration practice and practicing collaboration understanding. In J Genefke and F McDonal (Eds), Effective collaboration: managing obstacles to success, London: Palgrave.

Isabella LA (1990) Evolving interpretations as a change unfolds: how managers construe key organizational events, Academy of Management Journal, 33 (1): 7 41 .

Johnson-Laird PN (1983) Mental models: Towards a cognitive science of language, inference, and consciousness, Cambridge, Massachusetts, Harvard University Press.

Kahn WA (1990) Psychological conditions of personal engagement and disengagement at work, Academy of Management Journal, 33 (4): 692-724. 
Kelly C and Kelly J (1994) Who gets involved in collective action? Social psychological determinants of individual participation in trade unions, Human Relations, 47 (1): 63-88.

Landau JC, Shamir B, and Arthur MB (1992) Predictors of willingness to relocate for managerial and professional employees, Journal of Organizational Behavior, 13 (7): 667-680.

Lam A (2000) Tacit knowledge, organisational learning and societal institutions: an integrated framework, Organization Studies, 21 (3): 487-513.

May DR, Gilson R and Harter LM (2004) The psychological conditions of meaningfulness, safety, and availability and the engagement of the human spirit at work, Journal of Occupational and Organizational Psychology, 77(1): 11-37.

Mills PK, Hall JL, Leidecker JK, and Margulies N (1983) Flexiform: a model for professional service organizations, Academy of Management Review, 8 (1): 118-131.

Magnus JR, and Morgan, MS (1999) Methodology and tacit Knowledge: Two experiments in econometrics, Chichester/New York, John Wiley and Sons.

Molm LD (1994) Dependence and risk: transforming the structure of social exchange, Social Psychology Quarterly, 57 (3): 163-176.

Morris T and Empson L (1998) Organisation and expertise: an exploration of knowledge bases and management of accounting and consulting firms, Accounting, Organizations and Society, 23 (5): 609-624.

Morgan SE, Miller JK and Arasaratnam, LA (2003) Similarities and differences between African Americans' and European Americans' attitudes, knowledge, and willingness to communicate about organ donation, Journal of Applied Social Psychology, 33 (4): 693 -715.

Nahapiet J and Ghoshal S (1998) Social capital, intellectual capital and the organisational advantage, Academy of Management Review, 23 (2): 242-266.

Newell S, Robertson M, Scarbrough H, and Swan J (2002) Managing knowledge work, New York, Palgrave.

Nonaka I and Takeuchi H (1995) The knowledge-creating company, New York, Oxford University Press.

Nuttin J (1987) Affective consequences of mere ownership: the name letter effect in twelve European languages, European Journal of Social Psychology, 17, (4): 381-402.

O'Dell C and Grayson CJ (1998) If only we knew what we know: The transfer of internal knowledge and best practise, New York, The Free Press.

Osterloh, M. and Frey, B. S. (2000). Motivation, knowledge transfer, and organizational forms. Organization Science, 11(5), 538-550.

Parsons M (2004) Effective knowledge management for law firm, Oxford, Oxford University Press. 
Perugeni M and Gallucci M (2001) Individual Differences and Social Norms: The distinction between Reciprocators and pro-socials, European Journal of Personality, 15, (1): 19-35.

Pierce JL, Kostova T, and Dirks, KT (2003) The state of psychological ownership: integrating and extending a century of research, Review of General Psychology, 7 (1): 84-107.

Polanyi M (1964) Personal knowledge: toward a post-critical philosophy, Chicago: University of Chicago Press.

Prentice DA (1987) Psychological correspondence of possessions, attitudes, and values, Journal of Personality and Social Psychology, 53 (December): 9931003 .

Reber AS (1993) Implicit learning and tacit Knowledge; an essay on cognitive unconsciousness. New York: Oxford University Press.

Rousseau DM (2005) I-deals: Idiosyncratic Deals Employees Bargain for Themselves M.E. Sharpe London.

Rudmin FW (1993) Property. In W Lonner and R Malpass (Eds.), Psychology and Culture, Boston: Allyn and Bacon.

Sammons P (2005) Buying knowledge: Effective acquisition of extend knowledge, Aldershot: Gower.

Scribner S (1986) Thinking in action: some characteristics of practical thought. In R.J Sternberg and RK Wagner (Eds), Practical intelligence: Nature and origins of competence in the everyday world. Cambridge: Cambridge University Press.

Singh T, Premarjan R.K. (2007) Antecedents to Knowledge Transfer: Trust and Culture, The South Asian Journal Of management, 14 (1): 93-104.

Smith, HA, McKeen, J D and Singh S (2007) Tacit knowledge transfer; making it happen, Journal of Information Science \& Technology, 4 (2): 23-44.

Steiner G (1978) Martin Heidegger, Chicago, University of Chicago Press.

Stilwell D, Liden R, Parsons C and Deconinck, J (1998) Transfer decision making: different decision models depending on the transfer conditions? Journal of Organizational Behavior, 19 (6): 539-557.

Sullivan JJ and Nonaka I (1986) The application of organizational learning theory to Japanese and American management, Journal of International Business Studies, 17 (3): 127-147.

Szulanski G (1996) Exploring internal stickiness: impediments to the transfer of best practice within the firm, Strategic Management Journal, 17 (Special Issue): 2744.

Svensson R (2000) Success strategies and knowledge transfer in cross-border consulting operations, Boston, Kluwer Academic Publishers.

Van de Ven AH and Johnson PE (2006) Knowledge for theory and practice Academy of Management Review, 31(4): 802-821. 
Von Krogh G, Ichijo K and Nonaka I. (2000) Enabling knowledge creation, Oxford, Oxford University.

Walsh, J,P, Henderson CM and Deighton J (1988) Negotiated belief structures and decision performance: An empirical investigation, Organizational Behaviour and Human Decision Processes, 42: 194-216.

Wang P, Tong TW and Koh, CP (2003) An integrated model of knowledge transfer from MNC parent to China subsidiary, Journal of World Business 169 (August): $1-15$.

Watson S and Hewett K (2006) A multi-theoretical model of knowledge transfer in organizations: determinants of knowledge contribution and knowledge reuse, Journal of Management Studies, 43, (2): 141-173.

Weick K and Roberts KH (1993) Collective mind in organizations: heedful interrelating on flight decks, Administrative Science Quarterly, 38 (3): 357-381.

Zander U (1991) Exploiting a technological edge - voluntary and involuntary dissemination of technology. $\mathrm{PhD}$ dissertation, Stockholm School of Economics.

Zhikun D, Fungfai N, Qiying C (2007) Personal constructs affecting interpersonal trust and willingness to share knowledge between architects in project design teams, Construction Management \& Economics, 25 (9): 937-950. 
Figure 1. The estimated distance of the eight indicator statements placed within the overall sample

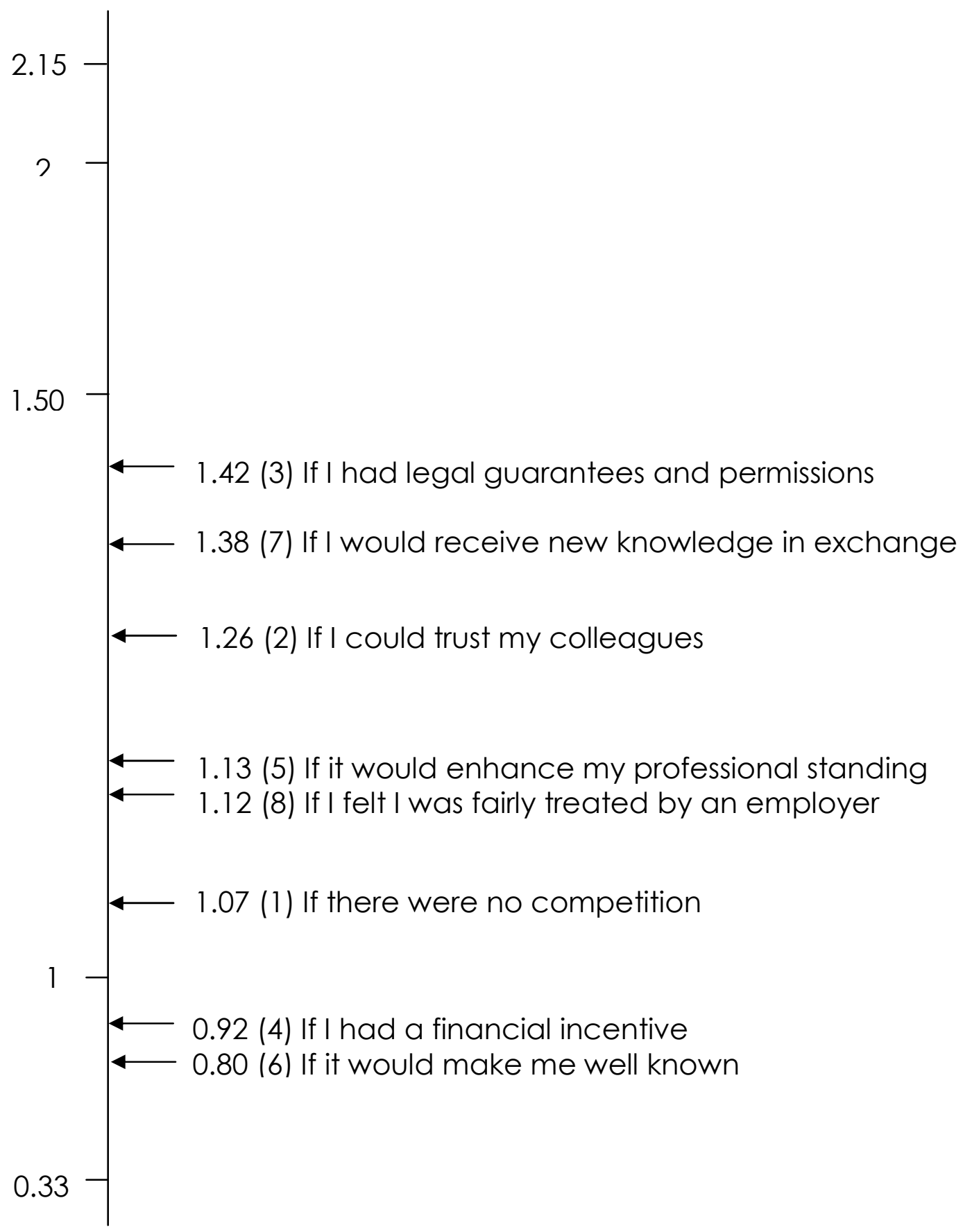


Table 1. $Z$ scores of the cumulative probabilities

\begin{tabular}{llllllll}
\hline indicators & 1 & 2 & 3 & 4 & 5 & 6 & 7 \\
\hline $\begin{array}{l}\text { 1 If there were } \\
\text { no competition }\end{array}$ & -1.03 & -0.70 & -0.49 & -0.05 & 0.36 & 0.96 & 1.00 \\
$\begin{array}{l}\text { 2 If I could trust } \\
\text { my colleagues }\end{array}$ & -1.28 & -0.91 & -0.70 & -0.22 & 0.13 & 0.88 & 1.00 \\
$\begin{array}{l}\text { 3 If I had legal } \\
\text { guarantees and }\end{array}$ & -1.47 & -1.08 & -0.87 & -0.38 & 0.03 & 0.68 & 1.00 \\
permissions \\
$\begin{array}{l}\text { 4 If I had a } \\
\text { financial }\end{array}$
\end{tabular}


Table 2. The differences between the categories

\begin{tabular}{llllll}
\hline Indicators & $2-1$ & $3-2$ & $4-3$ & $5-4$ & $6-5$ \\
\hline $\begin{array}{l}\text { 1 If there were no } \\
\text { competition }\end{array}$ & 0.33 & 0.21 & 0.44 & 0.41 & 0.60 \\
$\begin{array}{l}\text { 2 If I could trust my } \\
\text { colleagues }\end{array}$ & 0.37 & 0.21 & 0.48 & 0.35 & 0.75 \\
$\begin{array}{l}\text { 3 If I had legal guarantees } \\
\text { and permissions }\end{array}$ & 0.39 & 0.21 & 0.49 & 0.41 & 0.65 \\
$\begin{array}{l}\text { 4 If I had a financial } \\
\text { incentive }\end{array}$ & 0.36 & 0.22 & 0.44 & 0.39 & 0.59 \\
$\begin{array}{l}\text { 5 If it would enhance my } \\
\text { professional standing }\end{array}$ & 0.33 & 0.23 & 0.49 & 0.46 & 0.75 \\
$\begin{array}{l}\text { 6 If it would make me } \\
\text { well known }\end{array}$ & 0.32 & 0.25 & 0.51 & 0.53 & 0.67 \\
$\begin{array}{l}\text { 7 If I would receive new } \\
\text { knowledge in exchange }\end{array}$ & 0.25 & 0.19 & 0.35 & 0.47 & 0.83 \\
$\begin{array}{l}\text { 8 If I were fairly treated } \\
\text { by my employer }\end{array}$ & 0.28 & 0.16 & 0.54 & 0.38 & 0.81 \\
$\begin{array}{l}\text { Sum } \\
\text { N }\end{array}$ & 2.63 & 1.68 & 3.74 & 3.40 & 5.65 \\
Mean & 8 & 8 & 8 & 8 & 8 \\
\hline $\begin{array}{l}\text { Equal interval } \\
\text { assumption }\end{array}$ & 0.33 & 0.21 & 0.47 & 0.43 & 0.71 \\
\hline
\end{tabular}


Table 3. The boundaries minus the $\mathrm{z}$ scores from table 1

\begin{tabular}{|c|c|c|c|c|c|c|c|}
\hline indicators & B1-z1 & B2-z2 & B3-z3 & B4-z4 & B5-z5 & B6-z6 & Mean \\
\hline $\begin{array}{l}1 \text { If there were no } \\
\text { competition }\end{array}$ & 1.03 & 1.03 & 1.03 & 1.06 & 1.07 & 1.18 & 1.07 \\
\hline $\begin{array}{l}2 \text { If I could trust my } \\
\text { colleagues }\end{array}$ & 1.28 & 1.24 & 1.24 & 1.23 & 1.30 & 1.26 & 1.26 \\
\hline $\begin{array}{l}3 \text { If I had legal } \\
\text { guarantees and } \\
\text { permissions }\end{array}$ & 1.47 & 1.41 & 1.41 & 1.39 & 1.40 & 1.46 & 1.42 \\
\hline $\begin{array}{l}4 \text { If I had a } \\
\text { financial incentive }\end{array}$ & 0.91 & 0.88 & 0.87 & 0.90 & 0.93 & 1.05 & 0.92 \\
\hline $\begin{array}{l}5 \text { If it would } \\
\text { enhance my } \\
\text { professional } \\
\text { standing }\end{array}$ & 1.17 & 1.17 & 1.15 & 1.13 & 1.09 & 1.05 & 1.13 \\
\hline $\begin{array}{l}6 \text { If it would make } \\
\text { me well known }\end{array}$ & 0.87 & 0.88 & 0.84 & 0.80 & 0.69 & 0.73 & 0.80 \\
\hline $\begin{array}{l}7 \text { If I would receive } \\
\text { new knowledge in } \\
\text { exchange }\end{array}$ & 1.28 & 1.36 & 1.38 & 1.50 & 1.45 & 1.33 & 1.38 \\
\hline $\begin{array}{l}8 \text { If I were fairly } \\
\text { treated by my } \\
\text { employer }\end{array}$ & 1.08 & 1.13 & 1.18 & 1.11 & 1.15 & 1.05 & 1.12 \\
\hline
\end{tabular}

